\title{
The stretch-shortening cycle efficiency is dependent on the maturational stage
}

\section{A eficiência do ciclo alongamento-encurtamento é dependente do estágio maturacional}

\author{
Matheus Dantas ${ }^{1}$ \\ (1) https://orcid.org/0000-0002-1815-2251 \\ Victor Sabino de Queiros ${ }^{1}$ \\ (D) https://orcid.org/0000-0003-4117-0295 \\ Fabiano de Souza Fonseca ${ }^{2}$ \\ (1) https://orcid.org/0000-0002-9461-8797 \\ Paulo Francisco de Almeida-Neto ${ }^{1}$ \\ (D) https://orcid.org/0000-0002-2860-2260 \\ Rômulo Vasconcelos Teixeira ${ }^{1}$ \\ (D) https://orcid.org/0000-0002-9828-6961 \\ Leandro Medeiros da Silva ${ }^{1}$ \\ (D) https://orcid.org/0000-0002-0637-0155 \\ Felipe J. Aidar ${ }^{3}$ \\ (D) https://orcid.org/0000-0001-7378-4529 \\ Dihogo Gama de Matos ${ }^{4}$ \\ (D) https://orcid.org/0000-0002-7394-8527 \\ Breno Guilherme de Araújo Tinoco $\mathrm{Cabral}^{1}$ \\ (iD https://orcid.org/0000-0002-9966-9956
}

Abstract - Maturation interferes with physiological and mechanical aspects of muscle contraction. The aim of the present study was to compare the efficiency of the stretch-shortening cycle (SSC) between different maturation stages. One hundred forty six young people, with 72 boys and 74 girls, were recruited to participate in the study. Sexual maturation was measured and the group was stratified into adolescents ( $>3$ auto-tanner) and children ( $<2$ auto-tanner). Squat jump (SJ) and countermovement jump (CMJ) performance were measured to measure reactive force (RF) capacity, eccentric utilization ratio (EUR) and pre-stretch augmentation (PSAP). The children did not present statistical difference between SJ and CMJ $\left(\mathrm{t}_{(55)}=-1.93 ; \Delta=-0.61\right.$; $95 \% \mathrm{CI}=-1.24$ to $-0.02 ; \mathrm{p}=0.058)$, while the adolescents presented higher performance of $\mathrm{CMJ}\left(\mathrm{t}_{\mathrm{sg}}=-12.28 ; \Delta=-2.44 ; 95 \% \mathrm{CI}=-2.84\right.$ to $\left.-2.05 ; \mathrm{p}<0.001\right)$. In addition, adolescents had higher RF performance $\left(\mathrm{t}_{(144)}=5.18 ; \mathrm{p}<0.0001 ; 95 \% \mathrm{CI}=2.53\right.$ to 1.13$)$, $\mathrm{PSAP}\left(\mathrm{t}_{(144)}=4.38 ; \mathrm{p}\right.$ $<0.0001 ; 95 \% \mathrm{CI}=14.00$ to 5.29$)$ and $\mathrm{EUR}\left(\mathrm{t}_{(144)}=4.38 ; \mathrm{p}<0.0001 ; 95 \% \mathrm{CI}=0.14\right.$ to 0.05$)$. We conclude that more mature young people have better SSC utilization.

Key words: Muscle contraction; Athletic performance; Plyometric exercise; Sexual maturation; Puberty.

Resumo - Maturação interfere em aspectos fisiológicos e mecânicos da contração muscular. O objetivo do estudo foi comparar a eficiência do ciclo alongamento-encurtamento (SSC) em diferentes estágios maturacionais. Cento e quarenta e seis jovens, sendo 72 meninos e 74 meninas, foram recrutados para participar do estudo. Maturação sexual foi mensurada e o grupo foi estratificado em adolescentes ( $\geq 3$ e crianças (< estágio 2). Salto estático (SJ) e o salto contramovimento (CMJ) foram utilizados para mensurar a força reativa (RF), razão de utilização da excêntrica (EUR) e aumento do pré-estiramento $(P S A P)$. As crianças não apresentaram diferença significante entre $S J$ e $C M J\left(t_{(55)}=\right.$ -1.93; $\Delta=-0.61 ; 95 \% C I=-1.24$ to $-0.02 ; p=0.058)$, Enquanto que os adolescentes apresentaram maior desempenho de $C M J\left(t_{(80)}=-12.28 ; \Delta=-2.44 ; 95 \% C I=-2.84\right.$ to $\left.-2.05 ; p<0.001\right)$. Em adição, adolescentes apresentaram maior $R F\left(t_{(144)}=5.18 ; p<0.0001 ; 95 \% C I=2.53\right.$ to 1.13$), P S A P\left(t_{(144)}=\right.$ 4.38; $p<0.0001 ; 95 \% C I=14.00$ to 5.29$)$ e EUR ( $t_{(144)}=4.38 ; p<0.0001 ; 95 \% C I=0.14$ to 0.05$)$. Nós concluímos que jovens com mais maturados apresentam maior capacidade de utilização do SSC.

Palavras-chave: Contração muscular; Desempenho atlético; Exercício pliométrico; Maturidade sexual; Puberdade.
1 Federal University of Rio Grande do Norte. Graduate Program in Physical Education. Natal, RN. Brazil.

2 Federal University Rural Pernambuco. Departament of Physical Education. Recife, PE. Brazil.

3 Federal University of Sergipe. Department of Physical Education. São Cristovão, SE. Brazil.

4 McGill University. Institute of Parasitology. Montreal, Canada.

Received: March 23, 2020 Accepted: August 28, 2020

How to cite this article Dantas M, Queiros VS, Fonseca FS, Almeida-Neto PF, Teixeira RV, Silva LM, Aidar FJ, Matos DG, Cabral BGAT. The stretch-shortening cycle efficiency is dependent on the maturational stage. Rev Bras Cineantropom Desempenho Hum 2020, 22:e72597. D0l: http://dx.doi. org/10.1590/1980-0037.2020v22e72597

Copyright: This work is licensed under a Creative Commons Attribution 4.0 International License. 


\section{INTRODUCTION}

Jump is a human movement that requires complex motor coordination between the upper and lower body segments ${ }^{1}$. The jump action has been widely used as an important method to estimate the potency of lower limbs ${ }^{2,3}$, since the vertical jump presents an excellent practical applicability in the sporting sphere by simulating specific actions of game. Thus, jump is a widely used method that is easy to perform, non-fatiguing and requires a minimum of familiarization, but which can provide valuable information about the capabilities of the stretch-shortening cycle (SSC) in athletes ${ }^{4}$

The SSC is used in actions of jumps and sprints and is constantly studied in the science of the sport by its capacity to potentiate concentric actions after eccentric actions ${ }^{5}$. The elastic potential is transformed into mechanical energy so that performance maximization occurs with a lower metabolic cost and lower electromyographic activity ${ }^{6,7}$. A commonly used method for accessing the SSC is the jump height ${ }^{1}$, from the squat jump (SJ) and the Countermovement jump (CMJ). Based on the use of the vertical jump, it is possible to estimate the percentage of increase of pre-stretching $\{(\mathrm{CMJ}-\mathrm{SJ}) *(\mathrm{SJ})-1 * 100\}$ and reactive force $(\mathrm{RF})(\mathrm{RF}=\mathrm{CMJ}-\mathrm{SJ})^{8,9}$. Although the equations disregard the time domain in jump capacity, it has been confirmed that the reactive force has strong relation to the reactive force index (i.e., time domain computation) ${ }^{10}$.

In fact, the scientific literature has reported that actions involving SSC efficiently can produce higher performance of fast force and power. However, it has recently been suggested that SSC is developed throughout the maturation process and, therefore, youngsters in the early stages of the maturation process have lower cycle efficiency ${ }^{11}$. The data from the studies have indicated that adults have a greater capacity for SSC potentiation, and consequently, jump performance with the use of countermovement when compared to children ${ }^{5}$.

Several biomechanical and physiological factors can influence SSC efficiency throughout the maturational process. Among them, the literature highlights a greater tendon stiffness in young adults ( 22 years) compared to juniors $(\sim 13 \text { years })^{12}$, a greater stretch reflex in young adults when compared to prepubescent children ${ }^{13}$ and a decrease in co-contraction during walking in children aged 7 to 16 years $^{14}$. In addition to the increase in muscle volume and the percentage of fast contraction fibers from childhood to adulthood ${ }^{15}$.

Changes related to biological individuality may occur within the youth's own development process. Thus, coaches and sports scientists should be aware of these characteristics of the SSC (i.e., biomechanical, and physiological) for individualization of the prescription and periodization of the training, as well as be applied in the evaluation and diagnosis for performance. Therefore, the aim of the present study is to compare the stretch-shortening cycle efficiency in youngsters of different stages of maturation. Hypothesizing that children in a more accelerated maturation 
stage will present greater stretch-shortening cycle efficiency.

\section{METHODS}

\section{Participants}

The sample of the present study consisted of 146 youths, with 72 boys and 74 girls (see table 1) recreationally. The sample was divided into 2 groups stratified by the stage of sexual maturation, 56 children were allocated in the early stages (children) and 90 in the more advanced stages (adolescents). Participants were selected in a social project that encourages the practice of various sports modalities throughout the year, with training sessions conducted $2 \mathrm{x} /$ week. Participants who did not suffer muscle damage in the last 6 months, attended the project assiduously (> 85\%) and delivered the terms of assent and free and informed consent. Participants who completed creatine supplementation, underwent structured training in conjunction with the project or who opted out of the study were excluded from the sample. The study was approved by the local research ethics committee (CAAE: 1249937/2015) and followed the ethical principles recommended by the Declaration of Helsinki (2008). All participants and their guardians were verbally informed about the risks and benefits of the research. All participants signed the free and informed consent form and their guardians signed the free and informed consent form.

\section{Procedures}

Participants made two visits to our laboratory and were instructed not to perform vigorous activities within 48 hours prior to testing. On the first day a meeting was held with the youth, parents or guardians to explain the research procedures and to carry out the process of familiarization with the evaluation procedures, in addition to performing the assessment of body capacity through dual energy radiographic absorptiometry (DEXA) for characterization. On the second day, the anthropometric assessments, the stage of sexual maturation and the measurements of the physical tests were performed. The chronological age of participants was calculated from the sum of all months of life from birth to the day of collection divided by twelve. After the initial conversation, the participants were taken to a particular room where a mirror was attached to the wall next to a picture that contained the figures representing the 5 stages of sexual maturation. The participant was informed that he would enter the room alone to be able to observe and judge the most coherent option, by ticking the option on the board. The same was withdrawn from the room by a door opposite the entrance, to avoid contact with the others, and were directed again to the laboratory to evaluate the mass by means of the balance of precision of 100 grams (SANNY ${ }^{\circledR}$ ), followed by the evaluation of the stature by a stadiometer with a precision of 0.1 millimeters $\left(\mathrm{SANNY}^{\oplus} \mathrm{ES} 2020^{\circledR}\right.$, São Paulo, Brazil) and then the vertical jump tests were performed. 


\section{Measures}

For the measurement of sexual maturation, a drawing board showing 5 developmental figures of the breasts and / or genitalia and those of girls and boys $^{16,17}$ was used. We adopted the self-evaluation model for the present study, which was previously demonstrated with high reliability $(\mathrm{r}=\sim 0.80$ - $0.91 \%$ ) with the medical evaluation model, for boys and girls, when using the hair evaluation model puberty ${ }^{18}$. Following the operational definitions of Myer et al. ${ }^{19}$, participants were divided into 2 distinct groups based on sexual maturation. Those in stages 1 and 2 were called children and those who were in stage 3 or higher were called adolescents.

A Cefise ${ }^{\circledR}$ contact platform connected to the Jump Test Pro 2.10 software was used to measure jump height (São Paulo, Brazil). The jump tests were performed using the Jump System Pro jump platform with system-specific software $\left(\mathrm{CEFISE}^{\circledR}\right)$. Physical evaluations were preceded by standardized pre-heating consisting of low intensity races, stretches and jumps. The protocol consisted of 6 jumps, $3 \mathrm{SJ}$ and $3 \mathrm{CMJ}$, performed in an intercalated way with 30 seconds rest between each jump. Both vertical jump versus movement $(\mathrm{ICC}=0.97,95 \% \mathrm{CI}=0.94$ to 0.98$)$ and vertical jump (ICC $=0.97,95 \% \mathrm{CI}=0.94$ to 0.98 ) achieved good reproducibility measures. The squat jump was performed with the participant starting from an initial $90^{\circ}$ crouching position, with hands fixed at the waist and parallel feet. Participants took a signal from the evaluator after $~ 3-s$ in a static position to dissipate the energy potential of the eccentric phase of the movement. The jump action consisted of a single concentric action, without realizing a new descending phase of the center of gravity. The vertical jump against movement was performed with the participant standing with parallel feet and hands fixed at the waist. An eccentric action was performed at a self-selected depth to maximize jump height followed by concentric action at the highest and fastest velocity possible for SSC use. The best performance of each jump was used for analysis. The reactive force $[R F]$ was obtained by subtraction of the vertical jump against movement by the squat jump without against movement $[\mathrm{FR}=\mathrm{CMJ}-\mathrm{SJ}]^{8}$. Pre-stretch augmentation (PSAP) was obtained from the equation (CMJ - SJ / $\mathrm{SJ}^{-1}$ * 100 $)^{9}$. Eccentric utilization ratio (EUR) was calculated from the jump performance ratio $(\mathrm{CMJ} / \mathrm{SJ})^{20}$.

\section{Statistical Analyses}

The normality of the data was tested using the Shapiro-Wilk test and zscore of asymmetry and kurtosis (-1.96 to 1.96$)$. Sexual maturation was stratified in children (figure $\leq 2$ ) and adolescents (figure $\geq 3$ ). The t-test for independent samples was used to compare the means of SJ vs SJ, CMJ vs CMJ, RF vs RF, PSAP vs PSAP and EUR vs EUR between groups. The t-test for paired samples was used for SJ vs. CMJ comparisons within the same group. The Mann-Whitney $\mathrm{U}$ test was used to compare the group that used SSC efficiently versus the group that did not use it. A significance level of 5\% was adopted for all analyzes. 


\section{RESULTS}

Table 1 shows the description of the sample. Adolescents were older $\left(t_{(140.65)}\right.$ $=-7.36 ; \mathrm{p}<0.001 ; 95 \% \mathrm{CI}=-3.21$ to -1.85$)$, as well as higher mass $\left(\mathrm{t}_{(144)}=\right.$ $-5.68 ; \mathrm{p}<0.001 ; 95 \% \mathrm{CI}=-14.57$ to -7.05$)$, height $\left(\mathrm{t}_{(144)}=-8.43 ; \mathrm{p}<0.001\right.$; $95 \% \mathrm{CI}=-0.18$ to -0.11$)$ and $\mathrm{BMI}\left(\mathrm{t}_{(144)}=-2.46 ; \mathrm{p}<0.001 ; 95 \% \mathrm{CI}=-2.14\right.$ to -0.23$)$. While there was no difference for fat mass $\left(\mathrm{t}_{(144)}=-1.24 ; \mathrm{p}=\right.$ $0.215 ; 95 \% \mathrm{CI}=-2.75$ to 0.62 ), a statistical difference was found for lean mass $\left(\mathrm{t}_{(132.25)}=-6.97 ; \mathrm{p}<0.00195 \% \mathrm{CI}=-12.18\right.$ to -6.62$)$.

Table 1. Descriptive analysis of the sample (mean \pm standard deviation).

\begin{tabular}{lccc}
\hline & Children & Adolescents & P-value \\
\hline Age & $11.33 \pm 1.73$ & $13.86 \pm 2.40$ & $>0.001$ \\
Weight $(\mathrm{kg})$ & $37.42 \pm 11.88$ & $48.24 \pm 10.71$ & $>0.001$ \\
Height $(\mathrm{m})$ & $1.44 \pm 0.10$ & $1.59 \pm 0.10$ & $>0.001$ \\
Body mass index & $17.55 \pm 3.27$ & $18.74 \pm 2.53$ & 0.015 \\
Fat mass & $11.19 \pm 5.32$ & $12.25 \pm 4.81$ & 0.215 \\
Lean mass & $24.47 \pm 7.32$ & $33.86 \pm 8.79$ & $>0.001$ \\
\hline
\end{tabular}

Figure 1 presents the comparison of $\mathrm{CMJ}$ and SJ performance between the same subjects. The children showed no statistical difference between the jumping actions $\mathrm{t}_{(55)}=-1.93 ; \Delta=-0.61 ; 95 \% \mathrm{CI}=-1.24$ to $-0.02 ; \mathrm{p}=0.058 ; \mathrm{r}$ $=0.79$ ). The adolescents presented statistical difference between the jumping actions $\left(\mathrm{t}_{(89)}=-12.28 ; \Delta=-2.44 ; 95 \% \mathrm{CI}=-2.84\right.$ to $\left.-2.05 ; \mathrm{p}<0.001 ; \mathrm{r}=0.97\right)$.

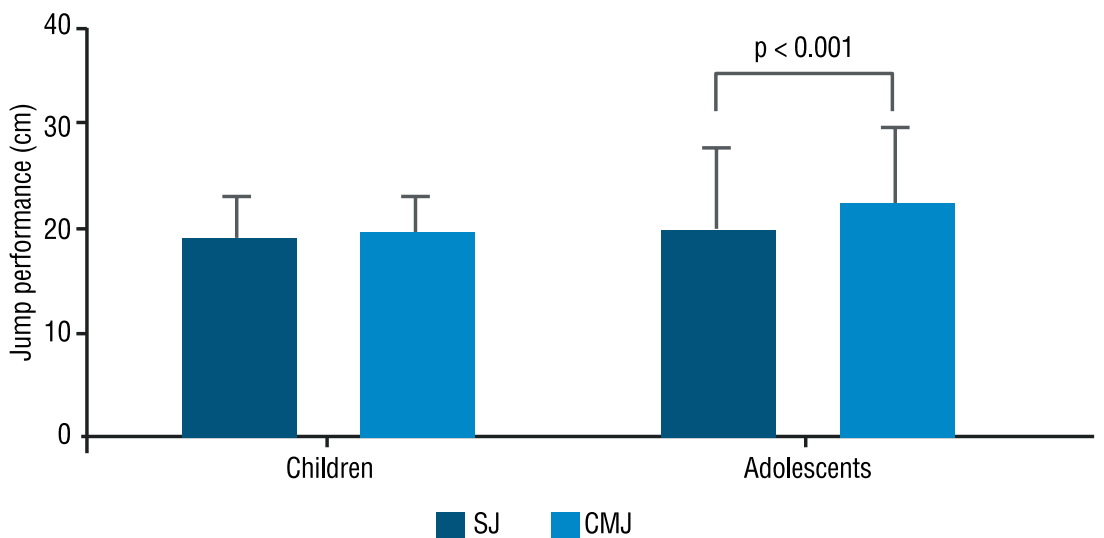

Figure 1. Comparison between performance in different types of jumps stratified by maturation stage.

Figure 2 describes the comparison between jumping performance between children and adolescents. The data show no statistical difference for $\mathrm{SJ}\left(\mathrm{t}_{(144)}=1.065 ; \mathrm{p}=0.289 ; 95 \% \mathrm{CI}=-2.76\right.$ to 0.83$)$, while $\mathrm{CMJ}$ showed a difference between groups $\left(\mathrm{t}_{(144)}=3.106 ; \mathrm{p}=0.002 ; 95 \% \mathrm{CI}=4.59\right.$ to 1.02). In addition, the reactive force $\left(\mathrm{t}_{(144)}=5.18 ; \mathrm{p}<0.0001 ; 95 \% \mathrm{CI}=\right.$ 2.53 to 1.13$), \operatorname{PSAP}\left(\mathrm{t}_{(144)}=4.38 ; \mathrm{p}<0.0001 ; 95 \% \mathrm{CI}=14.00\right.$ to 5.29$)$ and $\operatorname{EUR}\left(\mathrm{t}_{(144)}=4.38 ; \mathrm{p}<0.0001 ; 95 \% \mathrm{CI}=0.14\right.$ to 0.05$)$ showed significant differences between the groups. 

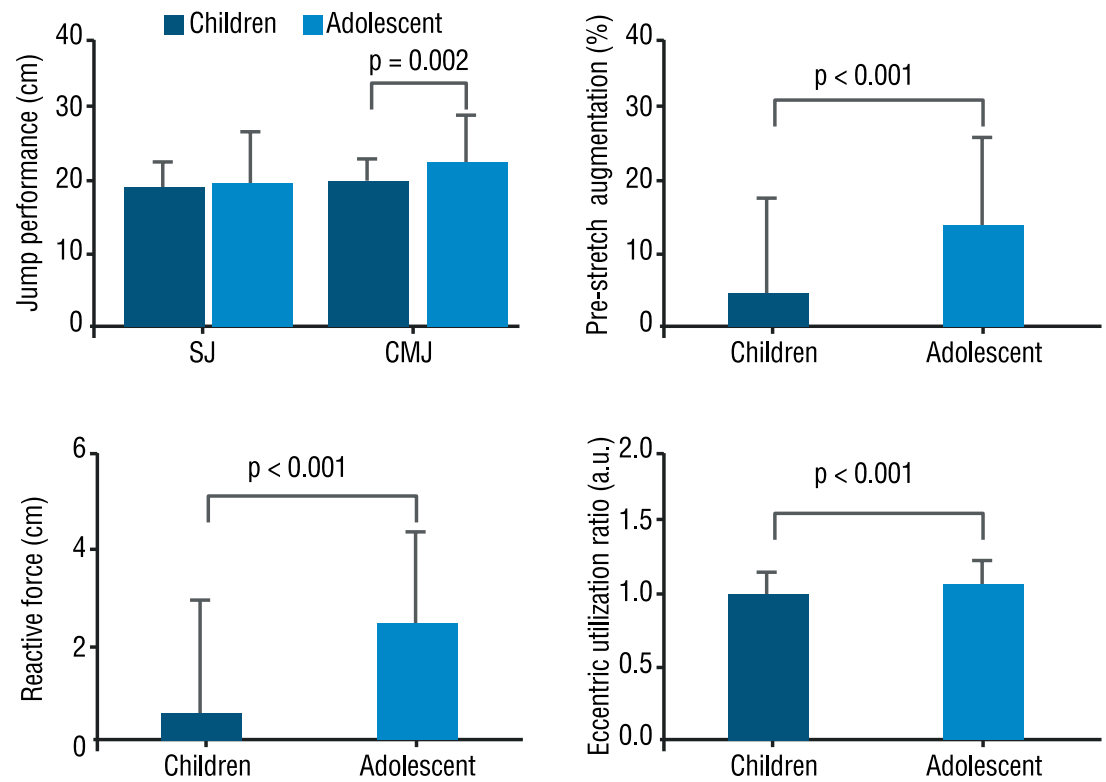

Figure 2. Efficiency of the stretch-shortening cycle at different stages of maturation.

Figure 3 shows an individual efficiency analysis of the stretch-shortening cycle. $39.3 \%$ of the children showed no gains in jump performance after using the eccentric phase. For the group of adolescents, only 13.3\% showed no gains after using the SSC.

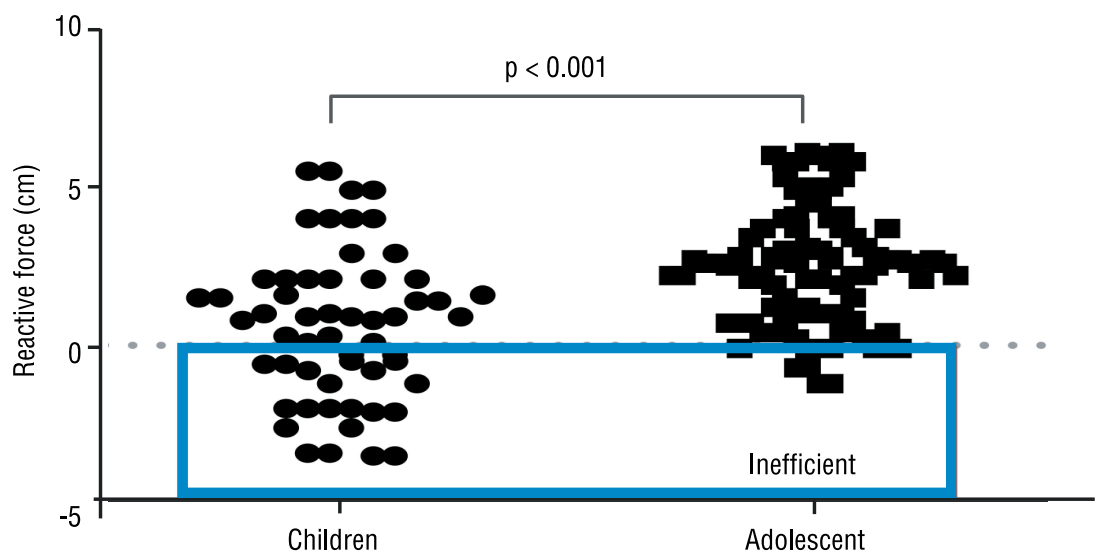

Figure 3. Analysis of participants making efficient use of SSC.

Table 2 reports the comparison between participants who use and do not use SSC efficiently stratified by maturity stage. Among children, it was identified that the group that uses SSC efficiently is older $(\mathrm{U}=576 ; \mathrm{p}$ $=0.001)$ and taller $(\mathrm{U}=532 ; \mathrm{p}=0.008)$. There was no statistical difference between adolescents.

\section{DISCUSSION}

The maturation process promotes several changes in the body, repercussions on physical valences that are determinant for sports performance and 
Table 2. Comparison between participants who use and do not use SSC efficiently stratified by maturity stage.

\begin{tabular}{lcccc}
\hline & \multicolumn{2}{c}{ Children } & \multicolumn{2}{c}{ Adolescent } \\
\cline { 2 - 5 } & $\begin{array}{c}\text { Inefficient } \\
(\mathrm{n}=22)\end{array}$ & $\begin{array}{c}\text { Efficient } \\
(\mathrm{n}=34)\end{array}$ & $\begin{array}{c}\text { Inefficient } \\
(\mathrm{n}=12)\end{array}$ & $\begin{array}{c}\text { Efficient } \\
(\mathrm{n}=78)\end{array}$ \\
\hline Age & $10,70(1,65)$ & $11,58(1,11)^{\mathrm{a}}$ & $14,55(1,80)$ & $13,22(4,14)$ \\
Weight $(\mathrm{kg})$ & $34,20(8,50)$ & $33,20(15,77)$ & $49,30(15,30)$ & $46,80(13,50)$ \\
\hline Height & $1,43(0,13)$ & $1,48(0,11)^{\mathrm{a}}$ & $1,58(0,09)$ & $1,60(0,14)$ \\
Body mass index & $17,31(3,44)$ & $16,27(4,34)$ & $18,87(2,87)$ & $18,48(3,67)$ \\
Fat mass & $11,04(5,25)$ & $9,02(5,98)$ & $9,31(10,82)$ & $10,73(5,63)$ \\
Lean mass & $21,43(4,34)$ & $23,73(6,20)$ & $32,85(11,85)$ & $32,45(13,61)$ \\
\hline
\end{tabular}

Note. a Statistical difference for inefficient children $(p<0.01)$.

dependent on the use of the stretching-shortening cycle. Therefore, the hypothesis of the present study was that the adolescents presented greater SSC efficiency. In our study it was identified that the SSC seems to be more effective in adolescents who went through the puberty process than in prepubescent children. In addition, it was identified that the proportion of subjects who are not able to enhance performance after SSC use decreases throughout the maturation process. Among children, the group that does not have efficient use is younger and has shorter stature, whereas in adolescents the ability to use SSC seems not to be associated with body composition and maturation.

The data of the present study report that children do not present statistical differences between the SJ and the CMJ, while the adolescent group obtained better performance for the CMJ (Figure 1). The main difference between the actions of the jump is the eccentric action in the CMJ, whereas the period in isometry in the SJ dissipates the energy in the form of heat ${ }^{21}$ before the concentric action. Literature reports that adults can improve their jumping performance by 18-30\% with SSC action, while children only improve by about $1-5 \% \%^{5,22}$. When we compared the performance by sexual maturation, the children ones showed an improvement of $~ 3 \%$ while their adolescent pairs improved performance by $12 \%$ (data from the present study).

A previous study has shown that during jumping action there is greater variability during the eccentric phase of movement, especially for pre-growth young growth ${ }^{23}$. The authors suggest that this phase requires high motor control, so children would be more harmed than their older peers. Moreover, the eccentric phase is essentially required for the storage of potential energy for subsequent concentric action ${ }^{6,7}$.

Morphological and neural factors are the main justifications for the development of SSC function according to the maturation process. A greater tendon stiffness was found in young adults compared to adolescents ${ }^{12}$, a greater stretch reflex (18\%) in young adults when compared to prepubescent children ${ }^{13}$ and a decrease in co-contraction during walking in children aged 7 to 16 years $^{14}$. In addition to the increase in muscle volume and the percentage of fast contraction fibers from childhood to adulthood ${ }^{15}$. Although the number of longitudinal studies aimed at verifying the maturation of 
neuromuscular tissue is scarce, the case-control studies suggest that there is a maturation process, and it is favorable to use the $\mathrm{SSC}^{11}$.

Still in our study, it was identified that there are young people who are not able to use SSC to enhance performance. Although the proportion of cases decreases throughout the maturation process, there are cases among children and adolescents. In children, participants who had the ability to use SSC are older, as well as stature. However, there was no difference between adolescents. The maturation process can influence the use of SSC in the early stages of puberty. The inefficiency of adolescents may be associated with motor experience and / or training experience since power training is a means of developing the stretching-shortening cycle ${ }^{24}$.

Activities involving SSC of muscle activation are intrinsic to exercise and sports efforts ${ }^{26}$, as well as being a basis for understanding training methods such as plyometrics. This may justify the lower trainability of prepubescent children when compared to the pubescent and pubescent children $^{27,28}$. Studies have shown that less mature children are less responsive to training, and that a volume overload does not appear to promote more positive responses in children ${ }^{29,30}$. Therefore, it is likely that due to maturational factors, children are less responsive to training methods that use SSC. Thus, the primary goal of training should be learning aspects of the exercises and not necessarily immediate physical performance gain. Furthermore, we suggest studies that evaluate not only the effect of maturation on youth trainability, but also that verify the efficiency of the stretch-shortening cycle as a confounding factor in adapting to plyometric training.

As a limitation of our study, the way of measuring SSC efficiency may bias our analysis. However, although the calculation for reactive force measurement (CMJ - SJ) disregards a primary component for actions related to SSC (i.e., time of action), it was shown that among the calculations described in the literature (i.e, stretch and eccentric utilization ratio) is the variable that is most related to the measurement of the reactive force index (i.e., equation with jump and time domain) ${ }^{10}$.

\section{CONCLUSION}

The present study demonstrated that youngsters at a more mature stage of maturation have greater stretch-shortening cycle efficiency and consequently present better performance for actions that use the cycle when compared to youngsters with delayed maturation. Moreover, we show that there are not able to use SSC to enhance jumping action. Our data have the potential to guide and plan the training and evaluation processes that make use of the stretching-shortening cycle for children.

\section{Acknowledgments}

We thank CNPq for the financial support and the Biodynamic Laboratory of the movement that gave space for the study. We thank to Biodynamic laboratory by support in research. 


\section{COMPLIANCE WITH ETHICAL STANDARDS}

\section{Funding}

Scholarship provided by the CAPES Foundation.

\section{Ethical approval}

Ethical approval was obtained from the Institutional Ethics Board Federal University of Rio Grande do Norte (CAAE: 1249937/2015), and the protocol was written in accordance with the standards established by the Declaration of Helsinki.

\section{Conflict of interest statement}

The authors have no conflict of interests to declare.

\section{Authors contributions}

Conception and design of the experiment: MD, VSQ, FSF, PFAN, RVT, LMS, FJA, DGM, BGATC; Realization of the experiments: MD, VSQ, PFAN, LMS, BGATC; Data analysis: MD, FJA, DGM; Contribution with reagents/research materials/analysis tools: BGATC; Article Writing: MD, VSQ, FSF, BGATC. All authors read and approved the final version of the manuscript.

\section{REFERENCES}

1. Markovic G, Dizdar D, Jukic I, Cardinale M. Reliability and factorial validity of squat and countermovement jump tests. J Strength Cond Res 2004;18(3):551-555.

2. Pagaduan J, Schoenfeld BJ, Pojskic H. Systematic Review and Meta-Analysis on the Effect of Contrast Training on Vertical Jump Performance. Strength Cond J 2019;41(3):63-78.

3. Ryman SA, Arvidsson J, Haglund E. Jump height as performance indicator for the selection of youth football players to national teams. J Sports Med Phys Fitness 2019.

4. Gathercole R, Sporer B, StellingwerffT, Sleivert G. Alternative countermovementjump analysis to quantify acute neuromuscular fatigue. Int J Sports Physiol Perform 2015;10(1):84-92.

5. Lloyd RS, Oliver JL, Hughes MG, Williams CA. Reliability and validity of fieldbased measures of leg stiffness and reactive strength index in youths. J Sports Sci 2009;27(14):1565-1573.

6. Bosco C, Viitasalo J, Komi P, Luhtanen P. Combined effect of elastic energy and myoelectrical potentiation during stretch-shortening cycle exercise. Acta Physiol Scand 1982;114(4):557-565.

7. Henchoz Y, Malatesta D, Gremion G, Belli A. Effects of the transition time between muscle-tendon stretch and shortening on mechanical efficiency. Eur J Appl Physiol 2006;96(6):665-671.

8. Walshe AD, Wilson GJ, Murphy AJ. The validity and reliability of a test of lower body musculotendinous stiffness. Eur J Appl Physiol 1996;73(3):332.

9. Young WB. Laboratory strength assessment of athletes. New Stud Ath1 1995;10(1):89-96.

10. Suchomel TJ, Sole CJ, Stone MH. Comparison of Methods That Assess Lowerbody Stretch-Shortening Cycle Utilization. J Strength Cond Res 2016;30(2): 547-554. 
11. Radnor JM, Oliver JL, Waugh CM, Myer GD, Moore IS, Lloyd RS. The influence of growth and maturation on stretch-shortening cycle function in youth. Sports Med 2018;48(1):57-71.

12. Kubo K, Teshima T, Hirose N, Tsunoda N. A cross-sectional study of the plantar flexor muscle and tendon during growth. Int J Sports Med 2014;35(10):828-834.

13. Grosset J-F, Mora I, Lambertz D, Pérot C. Changes in stretch reflexes and muscle stiffness with age in prepubescent children. J Appl Physiol 2007;102(6):2352-2360.

14. Frost G, Dowling J, Dyson K, Bar-Or O. Cocontraction in three age groups of children during treadmill locomotion. J Electromyogr Kinesiol 1997;7(3):179-186.

15. Lexell J, Sjöström M, Nordlund A-S, Taylor CC. Growth and development of human muscle: a quantitative morphological study of whole vastus lateralis from childhood to adult age. Muscle Nerve Off J Am Assoc Electrodiagn Med 1992;15(3):404-409.

16. Marshall WA, Tanner JM. Variations in pattern of pubertal changes in girls. Arch Dis Child 1969;44(235):291.

17. Marshall WA, Tanner JM. Variations in the pattern of pubertal changes in boys. Arch Dis Child 1970;45(239):13-23.

18. Chavarro JE, Watkins DJ, Afeiche MC, Zhang Z, Sánchez BN, Cantonwine D, et al. Validity of self-assessed sexual maturation against physician assessments and hormone levels. J Pediatr. 2017;186:172-178.

19. Myer GD, Lloyd RS, Brent JL, Faigenbaum AD. How young is "too young" to start training? ACSMs Health Fit J 2013;17(5):14.

20. McGuigan MR, Doyle TL, Newton M, Edwards DJ, Nimphius S, Newton RU. Eccentric utilization ratio: effect of sport and phase of training. J Strength Cond Res 2006;20(4):992-995.

21. Kim S. An effect of the elastic energy stored in the muscle-tendon complex at two different coupling-time conditions during vertical jump. Adv Phys Educ 2013;3(01):10.

22. Bosco C, Montanari G, Tarkkai I, Latteri F, Cozzi M, Iachelli G, et al. The effect of pre-stretch on mechanical efficiency of human skeletal muscle. Acta Physiol Scand 1987;131(3):323-329.

23. Meylan CM, Cronin JB, Oliver JL, Hughes MG, McMaster Dt. The reliability of jump kinematics and kinetics in children of different maturity status. J Strength Cond Res 2012;26(4):1015-1026.

24. Jeffreys MA, De Ste Croix MBA, Lloyd RS, Oliver JL, Hughes JD. The Effect of Varying Plyometric Volume on Stretch-Shortening Cycle Capability in Collegiate Male Rugby Players. J Strength Cond Res 2019;33(1): 139-145.

25. Kyröläinen H, Komi PV, Häkkinen K, Ha KD. Effects of Power Training With Stretch-Shortening Cycle (SSC) Exercises of Upper Limbs in Untrained Women. J Strength Cond Res 1998;12(4):248-252.

26. Kallerud H, Gleeson N. Effects of stretching on performances involving stretchshortening cycles. Sports Med 2013;43(8):733-750.

27. Asadi A, Arazi H, Ramirez-Campillo R, Moran J, Izquierdo M. Influence of maturation stage on agility performance gains after plyometric training: a systematic review and meta-analysis. J Strength Cond Res 2017;31(9):2609-2617.

28. Meylan C, Cronin JB, Oliver J, Hopkins W, Contreras B. The effect of maturation on adaptations to strength training and detraining in 11-15-year-olds. Scand J Med Sci Sports 2014;24(3):e156-e164.

29. Bouguezzi R, Chaabene H, Negra Y, Ramirez-Campillo R, Jlalia Z, Mkaouer $\mathrm{B}$, et al. Effects of different plyometric training frequency on measures of athletic performance in prepuberal male soccer players. J Strength Cond Res 2018; 34(6): 1609-1617. 
30. Chaabene H, Negra Y. The effect of plyometric training volume on athletic performance in prepubertal male soccer players. Int J Sports Physiol Perform 2017;12(9):1205-1211.

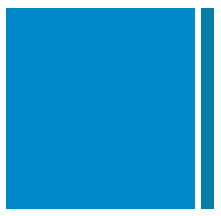

Corresponding author

Matheus Dantas

Federal University of Rio Grande do Norte

Department of Physical Education, Laboratory of Movement Biodynamics

Lagoa Nova, Natal, Rio Grande do Norte, Brazil.

Email: matheusp_dantas@ufrn.edu.br 